\title{
Safety of Ixekizumab Treatment for up to 5 Years in Adult Patients with Moderate-to-Severe Psoriasis: Results from Greater Than 17,000 Patient-Years of Exposure
}

\author{
April Armstrong - Carle Paul · Luis Puig • Wolf Henning Boehncke - Michael Freeman · Hideshi Torii • \\ Kim Papp · Christopher E. M. Griffiths · Andrew Blauvelt · Kristian Reich • Melinda Gooderham • \\ Tadashi Terui · Lisa Renda · Noah Agada · Wen Xu • Gaia Gallo · Mark G. Lebwohl
}

Received: August 8, 2019 / Published online: November 20, 2019

(C) The Author(s) 2019

\section{ABSTRACT}

Introduction: Long-term safety data are critical for evaluating therapies for psoriasis. Ixekizumab has demonstrated efficacy and is well tolerated for the treatment of moderate-to-severe plaque psoriasis. We examined the safety and tolerability of up to 5 years of ixekizumab therapy in patients with psoriasis.

Methods: Integrated safety data were analyzed from 13 ixekizumab clinical studies. Rates of treatment-emergent adverse events (TEAEs), serious AEs (SAEs) and AEs of special interest

Enhanced Digital Features To view enhanced digital features for this article go to https://doi.org/10.6084/ m9.figshare.10067021.

\section{A. Armstrong $(\bowtie)$}

Department of Clinical Research, Keck School of Medicine of the University of Southern California, Los Angeles, CA, USA

e-mail: armstrongpublication@gmail.com

\section{Paul}

Dermatology Department, Toulouse University Hospital (CHU), Paul Sabatier University, Toulouse, France

L. Puig

Hospital de la Santa Creu i Sant Pau, Universitat

Autònoma de Barcelona, Barcelona, Spain

W. H. Boehncke

Division of Dermatology and Venereology, Geneva

University Hospitals, Geneva, Switzerland were analyzed for the 12-week induction period in the combined pivotal studies, and for all pooled studies by year(s) of therapy and overall, reported as exposure-adjusted incidence rates (IRs) per 100 patient-years (p-y) and/or frequencies.

Results: Total ixekizumab exposure was $17,003.4$ p-y $\quad(N=5898) ; 2749$ patients had $\geq 4$ years of exposure. When compared across years of exposure, rates for AEs remained largely stable or declined, including TEAEs leading to discontinuation $(3.8 / 100 \mathrm{p}-\mathrm{y}$ in year 1 , declining to $2.0 / 100 \mathrm{p}-\mathrm{y}$ in year 5); SAEs (range 6.2-7.0/100 p-y); serious infections (range 1.3-1.7/100 p-y); nonmelanoma skin cancer (ranging from $0.5 / 100 \mathrm{p}-\mathrm{y}$ in year 1 to

\section{W. H. Boehncke}

Department of Pathology and Immunology,

University of Geneva, Geneva, Switzerland

\section{Freeman}

The Skin Centre, Benowa, QLD, Australia

\section{H. Torii}

Division of Dermatology, Tokyo Yamate Medical

Center, Tokyo, Japan

K. Papp

K Papp Clinical Research and Probity Medical Research, Waterloo, ON, Canada

C. E. M. Griffiths

Dermatology Centre, Salford Royal Hospital, University of Manchester, NIHR Manchester Biomedical Research Centre, Manchester, UK 
$0.2 / 100 \mathrm{p}-\mathrm{y}$ in years $4-5)$; other malignancies (range 0.4-0.6/100 p-y); inflammatory bowel disease including ulcerative colitis and Crohn's disease (IR 0.2/100 p-y); and major adverse cardiovascular events (MACE) (range 0.3-0.7/100 p-y). Candidiasis was reported in 327 patients (IR 1.9/100 p-y), with the majority identified as mucocutaneous. The rate of injection site reactions was $15.5 / 100$ p-y during year 1 and 2.0-2.3/100 p-y by years 3-5.

Conclusions: The decrease in rates of TEAEs and the stable rates of SAEs, other malignancies and MACE during up to 5 years of ixekizumab dosing are consistent with previous reports describing a favorable safety profile of ixekizumab following shorter durations of exposure. Funding: Eli Lilly and Company.

Keywords: Adverse events; Etanercept; IL-17; Integrated analysis; Ixekizumab; Safety; Psoriasis

A. Blauvelt

Oregon Medical Research Center, Portland, OR, USA

K. Reich

Center for Translational Research in Inflammatory Skin Diseases, Institute for Health Services Research in Dermatology and Nursing, University Medical Center Hamburg-Eppendorf, Hamburg, Germany

K. Reich

Skinflammation ${ }^{\circledR}$ Center, Hamburg, Germany

M. Gooderham

Centre for Dermatology and Probity Medical

Research, Peterborough, ON, Canada

T. Terui

Department of Dermatology, Nihon University

School of Medicine, Tokyo, Japan

L. Renda · N. Agada $\cdot$ W. Xu · G. Gallo

Eli Lilly and Company, Indianapolis, IN, USA

M. G. Lebwohl

Department of Dermatology, Icahn School of

Medicine at Mount Sinai, New York, NY, USA

\section{Key Summary Points}

Psoriasis is a chronic disease that requires long-term management; thus, long-term data on the safety and tolerability of psoriasis treatments are essential to inform patient management decisions.

We examined the long-term safety and tolerability of ixekizumab based on dosing of up to 5 years in 13 clinical trials in patients with moderate-to-severe psoriasis.

The incidence rates of treatment-emergent adverse events, serious adverse events and adverse events of special interest were either stable or decreased with increasing duration of ixekizumab therapy.

These findings are consistent with previous reports on ixekizumab and indicate that no new safety findings have emerged following longer durations of dosing.

\section{INTRODUCTION}

Moderate-to-severe psoriasis is a chronic immune-mediated inflammatory disease associated with substantial comorbidities $[1,2]$. At present, psoriasis requires long-term management; thus, long-term data on the safety and tolerability of treatments are essential to inform patient management decisions. Ixekizumab is a high-affinity monoclonal antibody that selectively targets interleukin (IL)-17A [3] and is approved for the treatment of moderate-to-severe plaque psoriasis based on the efficacy and consistent safety profile shown in the UNCOVER program. IL-17 plays a role in host mucocutaneous defense, and therefore IL-17 inhibition is linked to adverse events (AEs) in patients with candidiasis [4-7]. Furthermore, while the role of IL-17 in inflammatory bowel disease (IBD) and cardiovascular disease is 
unclear, IL-17 inhibitors are of special interest in treating these events [8-14]. Overall, the safety profile of ixekizumab has demonstrated comparability to biologic therapies with different mechanisms of action that are approved for plaque psoriasis, namely etanercept (UNCOVER-2 and -3 studies) [15] and ustekinumab (IXORA-S study) [16].

Two previous safety updates have addressed cumulative data from the ixekizumab development program. Strober et al. reported safety data from seven clinical trials (9 April 2015 data lock) [17]. Langley et al. provided an update of safety data from 11 clinical trials (15 September 2016 data lock) [18]. Here we report our results from an examination of the long-term safety and tolerability of ixekizumab based on $17,003.4$ patient-years (p-y) of ixekizumab exposure from 13 clinical trials (20 September 2018 data lock) in patients with psoriasis.

\section{METHODS}

The present analysis included the cumulative safety data covering up to 319 weeks of ixekizumab exposure integrated from 13 controlled and uncontrolled ixekizumab clinical studies on psoriasis, including three phase 3, randomized, double-blind, controlled pivotal clinical studies (UNCOVER-1, -2 and -3; Fig. 1) [15, 19]. All patients were $\geq 18$ years of age with moderateto-severe plaque psoriasis ( $\geq 10 \%$ body surface area [BSA] involvement, with the exception of the IXORA-Q study, in which the cutoff was $\geq 1 \%$ BSA involvement, as the study assessed genital psoriasis for which a lower threshold is considered) and had a Static Physician's Global Assessment of $\geq 3$ and a Psoriasis Area and Severity Index $\geq 12$ at baseline (excepting those in IXORA-Q). The UNCOVER-1, -2 and -3 and IXORA-Q [15, 19, 20] studies had 12-week, randomized, placebo-controlled periods, with the UNCOVER-2 and -3 studies having an additional etanercept arm up to week 12 . The IXORA-S study also had an ustekinumab treatment arm; however, the ustekinumab data are not analyzed herein due to limited patient numbers $(N=166)$ and duration of therapy (52 weeks) [16].
The protocols for all studies included in this analysis were approved by the Institutional Review Board or Ethics Committee at each participating site. All studies included in this analysis were conducted in accordance with the ethical principles of the Declaration of Helsinki. All eligible patients provided written informed consent before undergoing study-related procedures.

\section{Safety Assessments}

The AEs for the September 2018 update were classified based on the Medical Dictionary for Regulatory Activities version 21.0 (https://www. meddra.org/sites/default/files/guidance/file/ whatsnew_21_0_english.pdf); data for the placebo-controlled period of UNCOVER-1, -2 and -3 were based on version 17.0 (https://www. meddra.org/sites/default/files/guidance/file/ whatsnew_17_0_english.pdf). A treatmentemergent AE (TEAE) was an AE that first occurred or worsened in severity after baseline and within the treatment period. The lowest level terms have been used for the TEAE computation, and preferred terms are presented. Infections with an onset date $\leq 14$ days before or after neutrophil count collection were considered temporally associated with the corresponding neutropenia count. Safety topics of special interest included injection site reactions (ISRs), serious infections, candidiasis, major adverse cardiovascular events (MACE), nonmelanoma skin cancer (NMSC), malignancies (excluding NMSC) and IBD (including Crohn's disease and ulcerative colitis). The IBD events were adjudicated using the Registre Epidemiologique des Maladies de l'Appareil Digestif (EPIMAD) criteria [21, 22]. MACE were adjudicated by an external adjudication committee for ten of the 13 studies $(n=5697)$.

\section{Statistical Analyses}

Data are summarized overall from 13 clinical studies, and for the induction period (12 weeks) of three psoriasis clinical studies (UNCOVER-1, -2 and -3). All randomized patients who received $\geq 1$ dose of the study drug were 


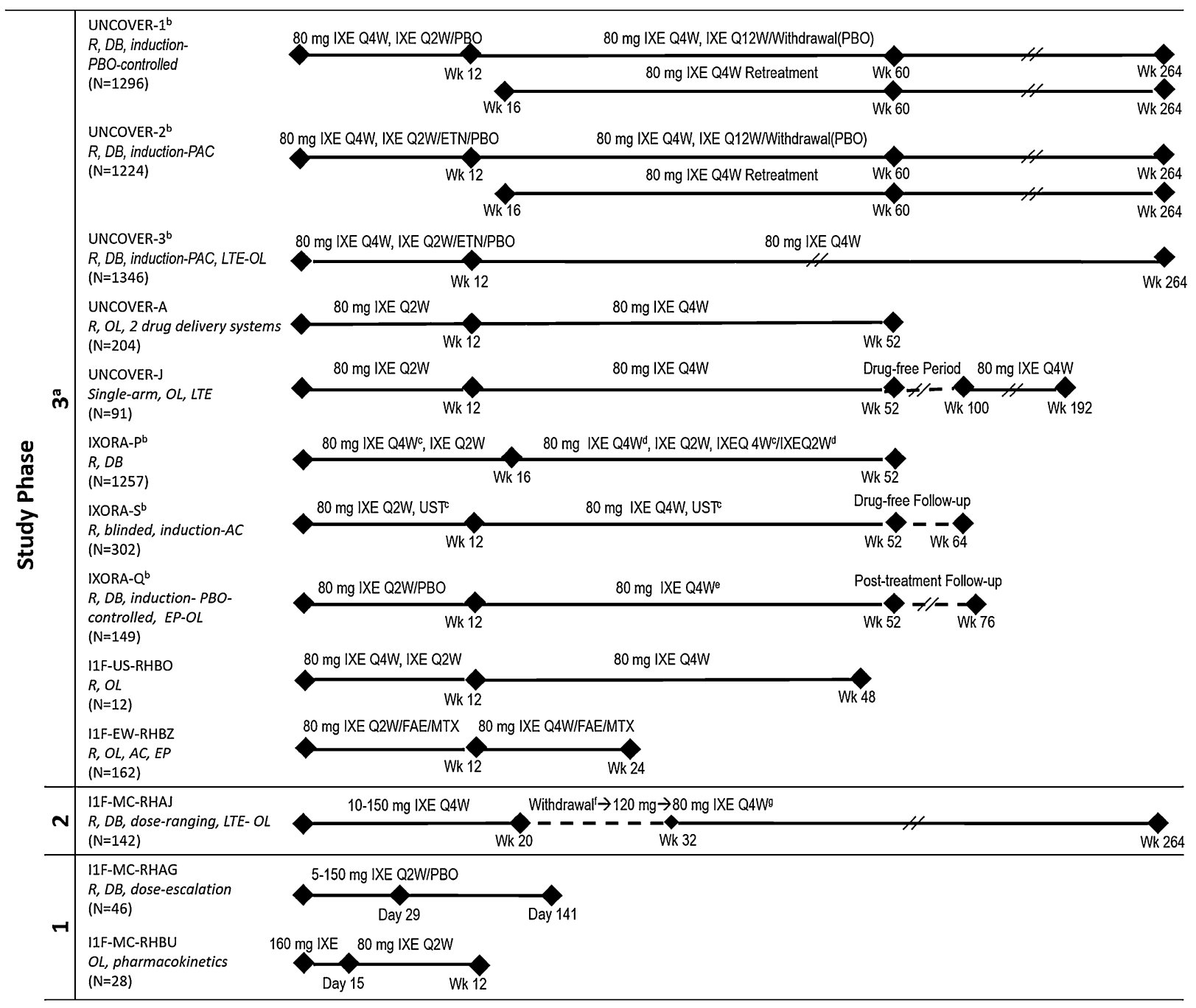

Fig. 1 Designs and numbers of patients for all studies included in the analysis. ${ }^{a}$ Patients receiving IXE received a 160-mg starting dose of IXE at week 0 prior to receiving $80 \mathrm{mg}$ IXE (Q4W or Q2W). ${ }^{\mathrm{b}}$ Global studies. ${ }^{\mathrm{c}} \mathrm{PBO}$ administered to maintain study blind. ${ }^{\mathrm{d} S}$ Step-up criteria determined if dosing increased from $80 \mathrm{mg}$ IXE Q4W to $80 \mathrm{mg}$ IXE Q2W based on whether a patient achieved sPGA $\geq 2$ at 2 consecutive visits during Wk 12 through Wk 40 . ${ }^{\mathrm{e}}$ Dosing increased from IXE Q4W to IXE Q2W based on investigator opinion from Wk 24 through Wk 40. ${ }^{f}$ Withdrawal period (Wks 20-32); a patient was eligible for treatment with $80 \mathrm{mg}$ IXE Q4W when improvement in PASI score from baseline was $<75 \%$ at any visit between $\mathrm{Wks}$ 20 and 32. ${ }^{g}$ Protocol amendment-mandated dose regimen. Clinicaltrials.gov numbers: UNCOVER-1, $-2,-3,-\mathrm{A}$ and $-\mathrm{J}$, NCT01474512, NCT01597245, NCT01646177, NCT01777191 and NCT01624233, respectively; IXORAP, $-S$ and -Q, NCT02513550, NCT02561806 and
NCT02718898, respectively; RHBO, NCT02387801; RHBZ, NCT02634801; RHAJ, NCT01107457; RHBU, NCT02993471. $A C$ active comparator, $D B$ double-blind, $E P$ optional extension period after Wk 24 during which patients received $80 \mathrm{mg}$ IXE Q4W up to Wk 60, ETN $50 \mathrm{mg}$ etanercept twice weekly, FAE fumaric acid esters $105-\mathrm{mg}$ starting dose followed by $215 \mathrm{mg}$ given orally $1-3$ times per day, IXE ixekizumab, IXE Q2W ixekizumab every 2 weeks, IXE $Q 4 W$ ixekizumab every 4 weeks, IXE Q12W ixekizumab every 12 weeks, $L T E$ long-term extension, $M T X$ methotrexate 7.5 -mg starting dose up to $30 \mathrm{mg}$ given orally once a week, $N$ number of patients, $O L$ open-label, $P A C$ placebocontrolled and active comparator, $P A S I$ Psoriasis Area Severity Index, $P B O$ placebo, $R$ randomized, $s P G A$ Static Physician's Global Assessment, UST $45 \mathrm{mg}$ ustekinumab given as subcutaneous injection for participants $\leq 100 \mathrm{~kg}$ and $90 \mathrm{mg}$ subcutaneous injection for participants $>100 \mathrm{~kg}$ at weeks $0,4,16,28$ and 40,Wk week 
included in the safety analysis population. Frequencies or exposure-adjusted incidence rates (IRs) of AEs are summarized overall and for some events of interest by 1-year (365-day) intervals. The IRs are expressed as number of unique patients with a particular category of event per $100 \mathrm{p}-\mathrm{y}$, using the entire duration of exposure during each interval. Multiple AEs that occurred in different intervals were counted multiple times.

As long-term control data were not available, previously published data for the placebo and ixekizumab groups from the large phase 3 UNCOVER studies are reported as time-adjusted IRs; baseline characteristics for the same patient groups are also presented.

\section{RESULTS}

A total of 5898 patients received at least one dose of ixekizumab across the 13 studies (Fig. 1). Approximately two-thirds of patients were in the large UNCOVER -1, -2 and -3 studies, which were ongoing as of the data cutoff for these analyses. Total patient exposure in the pooled analysis population was 17,003.4 p-y; 3009 patients had at least 3 years exposure and 2749 had at least 4 years of exposure (Fig. 2). Median duration of exposure was 1176 days, and maximum duration of exposure was 2236 days. For the overall ixekizumab population at baseline, mean age was 45.8 years, and $67.8 \%$ of patients were male (Table 1). Median duration of psoriasis symptoms at baseline was 16.7 years.

\section{Placebo-Controlled Period}

Results for the combined placebo-controlled periods of the UNCOVER-1, -2 and -3 studies have been presented previously [19]. When adjusted for patient exposure $(N=3119)$, the IR of any TEAE was higher with ixekizumab $(255.2 / 100$ p-y) than with placebo $(205.5 / 100$ p-y) (Table 2). The most common TEAE reported was nasopharyngitis for both placebo(IR 38.3/100 p-y) and ixekizumab- (IR 40.2/100 p-y) treated patients; the next most common TEAE was ISR (38.5/100 p-y) among ixekizumab-treated patients and upper respiratory

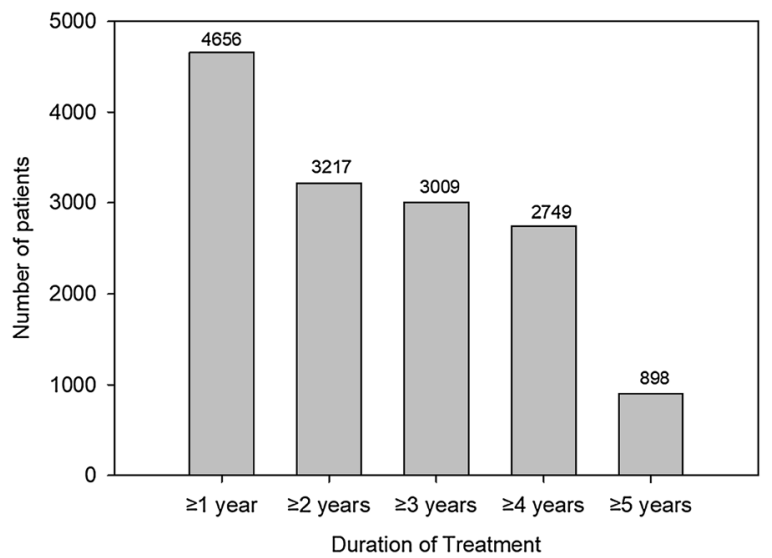

Fig. 2 Number of patients by treatment duration. $N$ (total number of patients $)=5898$; total exposure $=17,003.4$ patient-years

tract infection (15.6/100 p-y) for the placebo group. For the induction period of the combined UNCOVER-2 and -3 studies $(N=2562)$, which included etanercept as an active control, the rate of any TEAE for ixekizumab (250.5/100 p-y) was similar to that for etanercept (235.8/ 100 p-y), and the rates of nasopharyngitis and ISRs for etanercept were 32.5 and 47.3 per 100 p-y, respectively, versus 35.4 and 41.0 per 100 $\mathrm{p}-\mathrm{y}$, respectively, for the combined ixekizumab arms. Across the UNCOVER studies, for common TEAEs, IRs through 12 weeks were significantly higher among patients receiving ixekizumab than among those receiving placebo for ISR and injection site erythema. The IR of AEs leading to study drug discontinuation was 5.0/100 p-y for placebo and 9.2/100 p-y for patients receiving ixekizumab; for discontinuations due to ISRs, there were no AEs among placebo patients and an IR of 1.1 per 100 p-y ( $n=6 ; 0.3 \%)$ for patients receiving ixekizumab. The IR of serious AEs (SAEs) was 6.7 per 100 p-y for patients receiving placebo and 8.6 per 100 $\mathrm{p}$-y for patients receiving ixekizumab during the induction period. During the induction period of the combined UNCOVER -2 and -3 studies, ISRs and injection site erythema were both significantly higher for etanercept than for placebo, while the IR of AEs leading to etanercept discontinuation was 5.3 per $100 \mathrm{p}-\mathrm{y}$, with three patients discontinuing due to ISRs (IR 1.8/100 p-y; $0.4 \%)$. Similarly, the incidence of SAEs for 
Table 1 Baseline characteristics for the overall patient population

\begin{tabular}{|c|c|c|c|c|}
\hline Characteristics & $\begin{array}{l}\text { Placebo } \\
\text { (UNCOVER-1, -2 } \\
\text { and -3) }\end{array}$ & $\begin{array}{l}\text { Etanercept } \\
\text { (UNCOVER-2 } \\
\text { and -3) }\end{array}$ & $\begin{array}{l}\text { Ixekizumab } \\
\text { (UNCOVER-1, -2 } \\
\text { and }-3 \text { ) }\end{array}$ & $\begin{array}{l}\text { Ixekizumab } \\
\text { All }\end{array}$ \\
\hline Patients, $N$ & 791 & 739 & 2328 & 5898 \\
\hline Age, mean $(\mathrm{SD})$ years & $46.2(12.8)$ & $45.5(13.3)$ & $45.2(13.0)$ & $45.8(13.1)$ \\
\hline Male, $\%(n / N)$ & $70.7(559 / 791)$ & $68.2(504 / 739)$ & $66.7(1553 / 2328)$ & $\begin{array}{c}67.8(4000 / \\
5898)\end{array}$ \\
\hline \multicolumn{5}{|l|}{ Race, $\%(n / N)$} \\
\hline Asian & $4.3(34 / 791)$ & $2.6(19 / 735)$ & $3.7(86 / 2323)$ & $\begin{array}{c}6.9(408 / \\
5892)\end{array}$ \\
\hline African American & $3.3(26 / 791)$ & $3.1(23 / 735)$ & $2.1(48 / 2323)$ & $\begin{array}{c}2.9(168 / \\
5892)\end{array}$ \\
\hline White & $91.7(725 / 791)$ & $92.7(681 / 735)$ & $92.9(2159 / 2323)$ & $\begin{array}{c}87.8(5174 / \\
5892)\end{array}$ \\
\hline Others & $0.8(6 / 791)$ & $1.6(12 / 735)$ & $1.3(30 / 2323)$ & $\begin{array}{c}2.4(142 / \\
5892)\end{array}$ \\
\hline \multicolumn{5}{|l|}{ Geographic region, $\%(n / N)$} \\
\hline Asia & $1.6(13 / 791)$ & 0 & $0.9(20 / 2328)$ & $\begin{array}{c}3.9(232 / \\
5898)\end{array}$ \\
\hline North America & $50.9(403 / 791)$ & $51.8(383 / 739)$ & $51.4(1197 / 2328)$ & $\begin{array}{c}52.6(3100 / \\
5898)\end{array}$ \\
\hline Europe & $42.4(335 / 791)$ & $42.4(313 / 739)$ & $42.9(999 / 2328)$ & $\begin{array}{c}37.4(2205 / \\
5898)\end{array}$ \\
\hline Central/South America & $1.8(14 / 791)$ & $4.1(30 / 739)$ & $2.5(58 / 2328)$ & $\begin{array}{c}3.0(174 / \\
5898)\end{array}$ \\
\hline Australia & $3.3(26 / 791)$ & $1.8(13 / 739)$ & $2.3(54 / 2328)$ & $\begin{array}{c}2.8(165 / \\
5898)\end{array}$ \\
\hline $\mathrm{BMI}$, mean $\mathrm{kg} / \mathrm{m}^{2}(\mathrm{SD})$ & $30.5(7.2)$ & $31.0(7.4)$ & $30.5(7.1)$ & $30.6(7.3)$ \\
\hline \multicolumn{5}{|c|}{ Prior systemic therapy, \% $(n / N)$} \\
\hline Never & $35.8(283 / 791)$ & $39.6(293 / 739)$ & $34.7(808 / 2328)$ & $\begin{array}{l}35.7(2104 / \\
5898)\end{array}$ \\
\hline Nonbiologic only & $31.7(251 / 791)$ & $42.1(311 / 739)$ & $38.4(894 / 2328)$ & $\begin{array}{c}33.7(1986 / \\
5898)\end{array}$ \\
\hline Biologic only & $11.6(92 / 791)$ & $8.0(59 / 739)$ & $9.3(216 / 2328)$ & $\begin{array}{c}12.4(729 / \\
5898)\end{array}$ \\
\hline Biologic and nonbiologic & $20.9(165 / 791)$ & $10.3(76 / 739)$ & $17.6(410 / 2328)$ & $\begin{array}{c}18.3(1079 / \\
5898)\end{array}$ \\
\hline
\end{tabular}


Table 1 continued

\begin{tabular}{|c|c|c|c|c|}
\hline Characteristics & $\begin{array}{l}\text { Placebo } \\
\text { (UNCOVER-1, -2 } \\
\text { and -3) }\end{array}$ & $\begin{array}{l}\text { Etanercept } \\
\text { (UNCOVER-2 } \\
\text { and -3) }\end{array}$ & $\begin{array}{l}\text { Ixekizumab } \\
\text { (UNCOVER-1, -2 } \\
\text { and -3) }\end{array}$ & $\begin{array}{l}\text { Ixekizumab } \\
\text { All }\end{array}$ \\
\hline \multicolumn{5}{|l|}{ Prior biologic therapy, $\%(n / N)$} \\
\hline Never & $67.5(534 / 791)$ & $81.7(604 / 739)$ & $73.1(1702 / 2328)$ & $\begin{array}{l}69.3(4090 / \\
5898)\end{array}$ \\
\hline 1 & $19.6(155 / 791)$ & $13.7(101 / 739)$ & $16.3(379 / 2328)$ & $\begin{array}{l}19.4(1146 / \\
5898)\end{array}$ \\
\hline 2 & $7.1(56 / 791)$ & $3.0(22 / 739)$ & $6.2(144 / 2328)$ & $\begin{array}{c}6.5(384 / \\
5898)\end{array}$ \\
\hline$\geq 3$ & $5.8(46 / 791)$ & $1.6(12 / 739)$ & $4.4(103 / 2328)$ & $\begin{array}{c}4.7(278 / \\
5898)\end{array}$ \\
\hline $\begin{array}{l}\text { Duration of psoriasis symptoms, } \\
\text { mean years }(\mathrm{SD}) \text { [median] }\end{array}$ & $19.1(12.1)[16.7]$ & $18.5(12.1)[16.4]$ & $18.8(12.2)[16.9]$ & $\begin{array}{l}18.7(12.2) \\
{[16.7]}\end{array}$ \\
\hline Tobacco use, yes, $\%(n / N)$ & $39.5(310 / 784)$ & $37.1(274 / 739)$ & $37.6(872 / 2322)$ & $\begin{array}{c}14.8(874 / \\
5898)\end{array}$ \\
\hline
\end{tabular}

$B M I$ Body mass index, $N$ total patients evaluated, $n$ number of patients in category, $S D$ standard deviation

etanercept was 8.3 per 100 p-y during the induction period.

\section{Combined Periods of Ixekizumab Therapy}

Incidence rates for TEAEs for the combined ixekizumab treatment period were compared with either placebo or ixekizumab treatment during the induction period. Exposure-adjusted IRs for any TEAE were lower in the combined ixekizumab treatment period $(30.0 / 100$ p-y) than in placebo-controlled period (placebo 205.5/100 p-y or ixekizumab 255.2/100 p-y; Table 2). The same was true for the most common TEAEs of nasopharyngitis/viral upper respiratory infection $(8.9 / 100$ p-y overall vs. $38.3 /$ 100 p-y for placebo or 40.2/100 p-y for ixekizumab through 12 weeks) upper respiratory tract infection (5.4/100 p-y overall vs. $15.6 / 100$ p-y or 18.0/100 p-y); ISR (3.4/100 p-y vs. 5.0/100 p-y or 38.5/100 p-y) and headache (3.0/100 p-y vs. $12.8 / 100 \mathrm{p}-\mathrm{y}$ or $18.9 / 100 \mathrm{p}-\mathrm{y})$, which were more common among ixekizumab-treated patients than placebo-treated patients during the induction phase. The rates of AEs leading to study discontinuation, any SAEs and SAEs by body system generally decreased or remained static when compared between the induction period and the combined ixekizumab treatment period (Table 2).

To assess the impact of cumulative exposure on rates of important AEs, IRs were compared through $1,2,3,4$ and 5 years of treatment (Fig. 3). The exposure-adjusted IR of ISRs was 15.5 per $100 \mathrm{p}$-y during the first year of treatment and declined to a range of $2.0-2.3$ per 100 p-y by years 3-5 of treatment. Similarly, allergic reactions or hypersensitivities were reported at 9.9/100 p-y during the first year of treatment and declined from 5.1 to 3.8 per $100 \mathrm{p}$-y from years $2-5$. The IR for AEs leading to study discontinuation declined from 3.8/100 p-y in the first year of treatment to 2.0 per 100 p-y in the fifth year, while the IR for serious infections remained essentially constant (range 1.3-1.7 per 100 p-y). IRs of overall SAEs were relatively constant for each of the 1-year periods (range 6.2-7.0 per 100 p-y). The IRs of NMSC were 


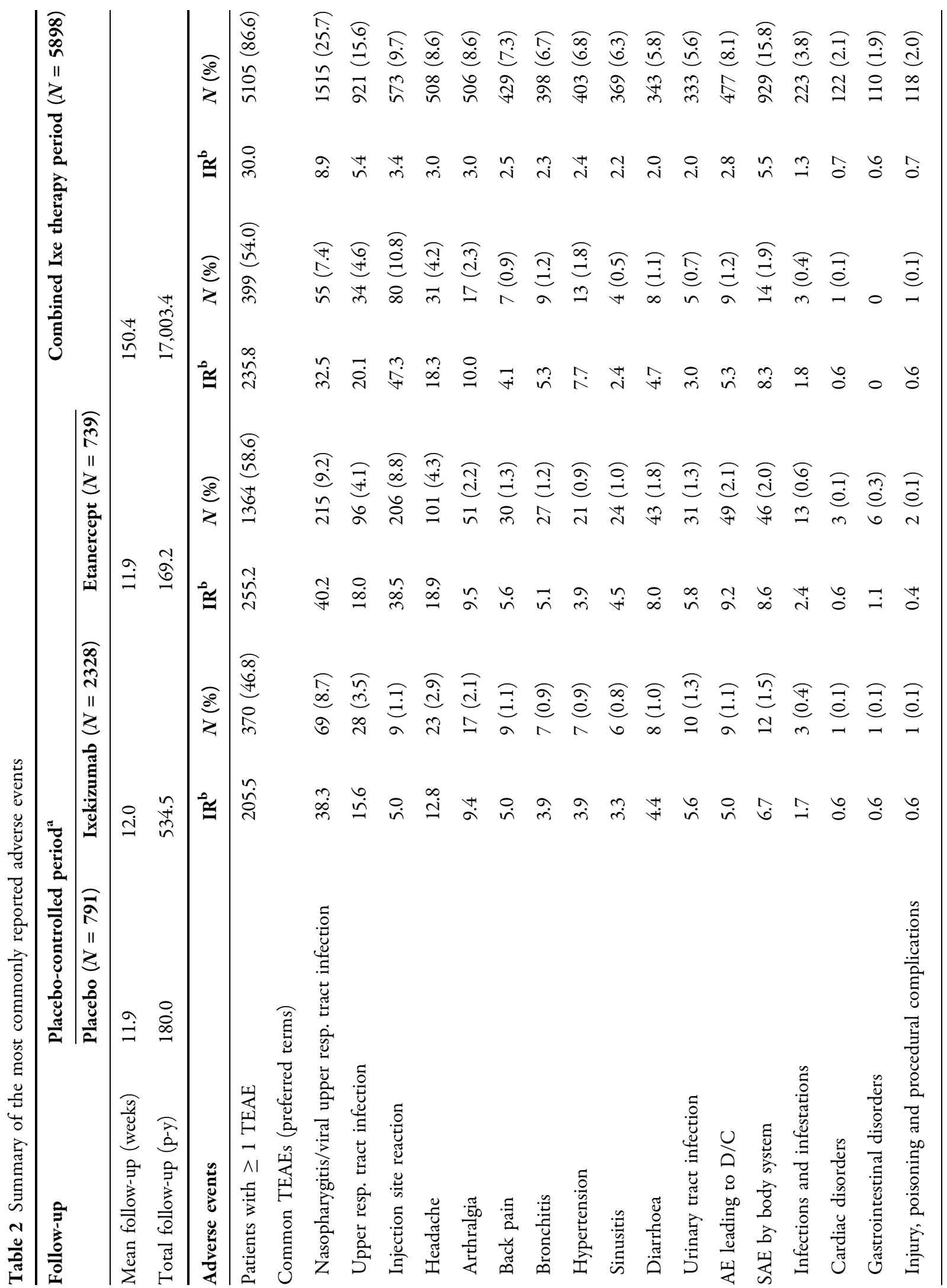




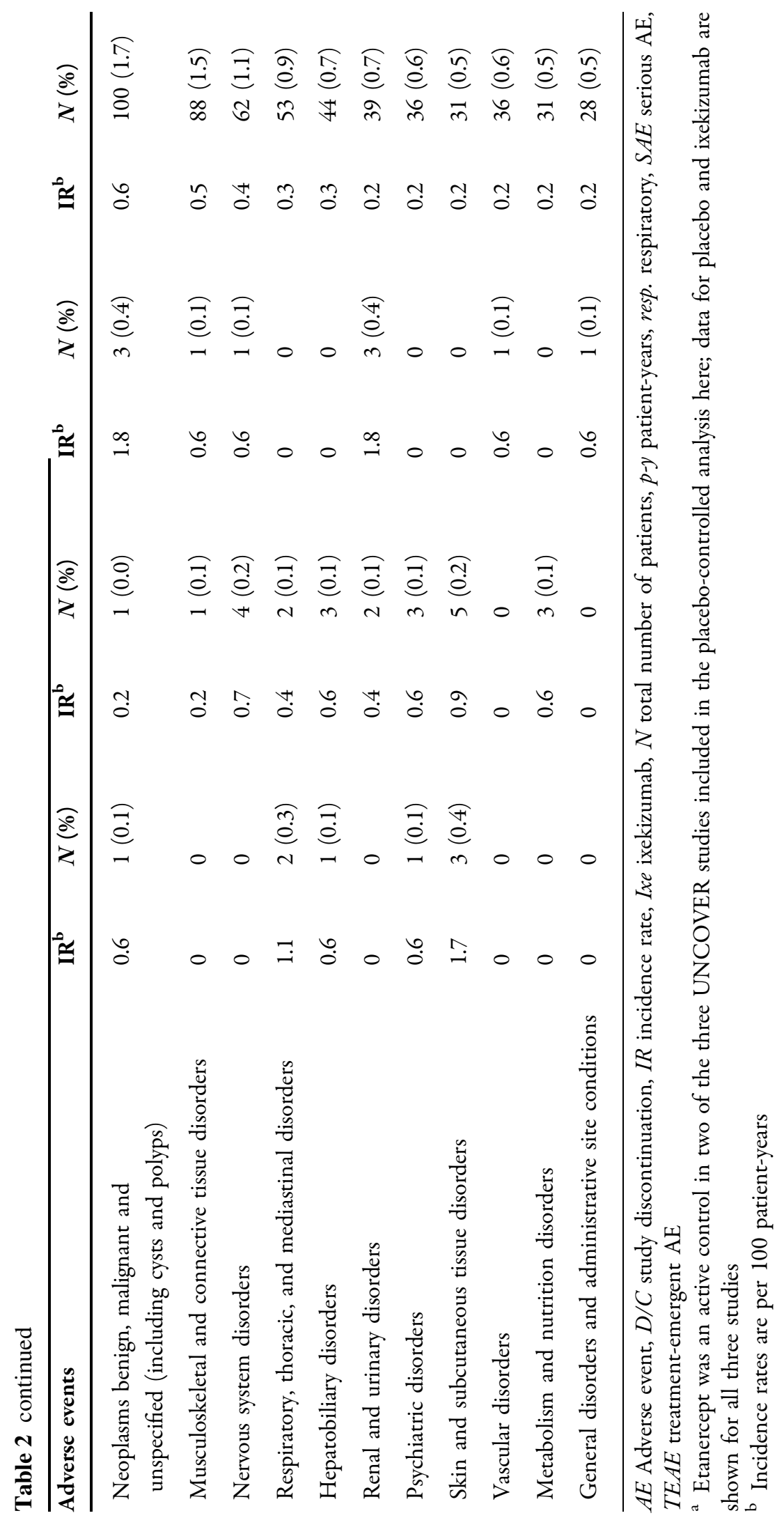




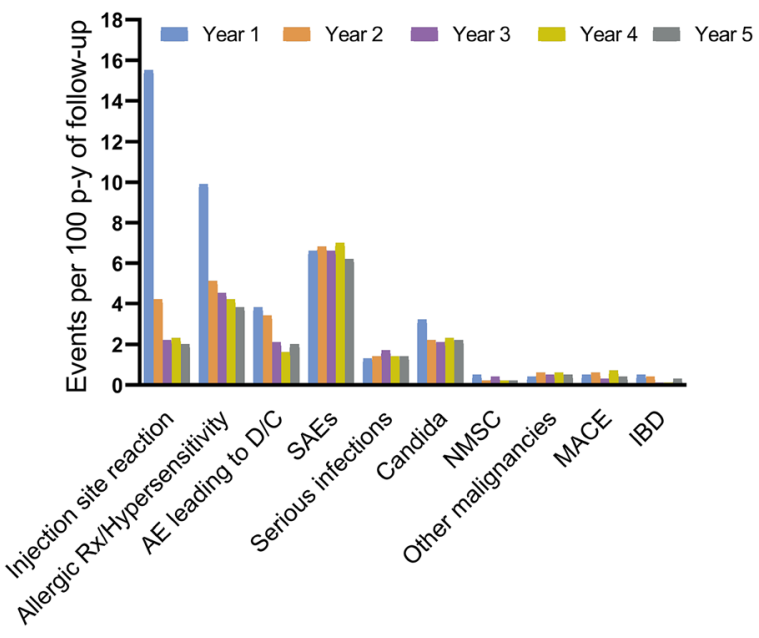

Fig. 3 Treatment-emergent adverse events per 100 patient-years by years of treatment. $A E$ Adverse event, $D / C$ study discontinuation, $I B D$ inflammatory bowel disease, $M A C E$ major adverse cardiovascular events, $N M S C$ non-melanoma skin cancer, $p-y$ patient-years, $R x$ reaction, $S A E$ serious adverse event

highest in the first year $(0.5 / 100$ p-y) and decreased or stayed the same in subsequent years (range 0.2-0.4 per $100 \mathrm{p}$-y), while IRs for other malignancies ranged from 0.4 per $100 \mathrm{p}-\mathrm{y}$ in the first year to 0.6 per $100 \mathrm{p}-\mathrm{y}$ in the fourth year. MACE occurred in 84/5697 patients, with an overall IR of 0.5 per 100 p-y (Table 3); although IRs varied across treatment years, no trend was observed for an increase over time. IRs (unadjudicated) of IBD ranged from a high of 0.5 in the first year to a low of 0.1 during the third and fourth years of treatment. The IRs of candidiasis were highest in the first year (3.2/ $100 \mathrm{p}-\mathrm{y})$ and then ranged from 2.1 to 2.3 per $100 \mathrm{p}-\mathrm{y}$ in subsequent years.

Thirty-four deaths were reported, with 32 deaths occurring during ixekizumab treatment (IR during treatment 0.2/100 p-y; range 0.1-0.3 per 100 p-y by year). For all deaths, causes were cardiac-related $(n=14)$, malignancies $(n=4)$, unknown $(n=5)$, respiratory causes $(n=3)$, trauma/accident $(n=3)$, severe hemorrhagic cerebral infarction $(n=1)$, death concomitant with severe senile dementia $(n=1)$, ulcerative colitis $(n=1)$, cholecystolithiasis $(n=1)$ and septic shock $(n=1)$. MACE accounted for most deaths, and none of the deaths were considered related to the study drug.
Table 3 Summary of treatment-emergent adverse events of special interest during combined ixekizumab dosing

\begin{tabular}{|c|c|c|}
\hline Treatment-emergent AEs & $N(\%)$ & $\mathbf{I R}^{\mathbf{a}}$ \\
\hline Patients treated & 5898 & \\
\hline Injection site reactions & $892(15.1)$ & 5.2 \\
\hline Hypersensitivity/allergic reactions & $876(14.9)$ & 5.2 \\
\hline Serious infections and infestations & $223(3.8)$ & 1.3 \\
\hline Oral candidiasis & $140(2.4)$ & 0.8 \\
\hline Malignancies & $131(2.2)$ & 0.8 \\
\hline NMSC & $51(0.9)$ & 0.3 \\
\hline $\begin{array}{l}\text { Other malignancies (excluding } \\
\text { NMSC) }\end{array}$ & $86(1.5)$ & 0.5 \\
\hline $\begin{array}{l}\text { Inflammatory bowel disease (narrow } \\
\text { terms) }\end{array}$ & $26(0.4)$ & 0.2 \\
\hline Inflammatory bowel disease & $1(0.0)$ & $<0.05$ \\
\hline Crohn's disease & $7(0.1)$ & $<0.05$ \\
\hline Ulcerative colitis & $18(0.3)$ & 0.1 \\
\hline MACE, adjudicated $(n=5697)$ & $84(1.5)$ & 0.5 \\
\hline Vascular death & $20(0.4)$ & 0.1 \\
\hline Myocardial infarction, nonfatal & $45(0.8)$ & 0.3 \\
\hline Stroke, nonfatal & $20(0.4)$ & 0.1 \\
\hline
\end{tabular}

$A E$ Adverse event; $I R$ incidence rate; $M A C E$ major adverse cardiovascular events, $N$ total number of patients, $n$ number of patients in category, NMSC non-melanoma skin cancer

${ }^{a}$ Incidence rates are per 100 patient-years

\section{Adverse Events of Special Interest}

As assessed based on years of treatment, IRs were generally constant or decreasing for ISRs, allergic reactions/hypersensitivity, serious infections, candidiasis, MACE, NMSC, other malignancies and IBD across the treatment periods (Fig. 2).

\section{Administration Site or Drug Reactions}

As noted above, the IRs for ISRs, as well as for allergic reactions/hypersensitivity, decreased over time through the 5 years of the study. 
One or more ISRs were reported for $15.1 \%$ of patients (Table 3), with 10.0, 4.5 and $0.6 \%$ experiencing mild, moderate and severe reactions, respectively, at an overall IR of 5.2 per $100 \mathrm{p}-\mathrm{y}$. The most commonly reported specific terms were ISR (IR 3.4/100 p-y), injection site erythema (1.1/100 p-y) and injection site pain $(0.6 / 100$ p-y). A total of 13 patients discontinued the study drug due to injection site-related TEAEs $(0.1 / 100 \quad \mathrm{p}-\mathrm{y})$. The most frequently reported allergic events (IR $\geq 0.5$ ) were contact dermatitis (IR 1.1/100 p-y), eczema $(1.0 / 100$ p-y), urticaria $(0.6 / 100$ p-y), dermatitis $(0.5 / 100$ $\mathrm{p}-\mathrm{y})$, allergic rhinitis $(0.5 / 100 \mathrm{p}-\mathrm{y})$ and rash $(0.5 / 100 \mathrm{p}-\mathrm{y})$. There was one case of worsening eczematous reaction that was considered a possible paradoxical reaction, but the patient recovered and continued in the study. Four SAEs of pustular psoriasis were reported. One event occurred after an upper respiratory tract infection; the patient recovered and continued in the clinical trial. Of three cases of pustular psoriasis events, two were considered related to the study drug by the investigator, and the third case was considered unrelated; all three patients discontinued the study drug. There were reports of potential anaphylaxis events; however, upon review, none occurred in temporal relationship to the administration of ixekizumab, and no confirmed cases of ixekizumab-related anaphylaxis have been identified in any clinical studies.

\section{Infections}

Infections overall were more common during the first year of treatment (IR 56.6; 95\% confidence interval [CI] 54.6, 58.6/100 p-y) versus later years (IR range 35.8 [95\% CI 33.7, 38.0] to 41.2 [95\% CI 39.1, 43.4]/100 p-y). In addition to the upper respiratory tract infections described above, the most common infections overall were bronchitis (IR 2.3/100 p-y), sinusitis (IR 2.2/100 p-y) and urinary tract infection (IR 2.0/100 p-y; Table 4). Infections and infestations were largely mild to moderate in severity and seldom led to discontinuation of the study drug (IR for discontinuation due to infection $0.4 / 100 \mathrm{p}-\mathrm{y})$. The most common serious infections (IR $\geq 0.1 / 100 \mathrm{p}$-y) were cellulitis $(n=40 ; \quad$ IR $0.2 / 100$ p-y); pneumonia
Table 4 Infections

\begin{tabular}{lcc}
\hline Category & $\begin{array}{c}\text { Combined } \\
\text { ixekizumab } \\
(\boldsymbol{N}=\mathbf{5 8 9 8})\end{array}$ \\
\cline { 2 - 3 } & $\boldsymbol{n}(\%)$ & $\mathbf{I R}^{\mathbf{a}}$ \\
\hline Patients with $\geq 1$ infection & $3859(65.4)$ & 22.7 \\
Nasopharyngitis & $1515(25.7)$ & 8.9 \\
Upper respiratory tract infection & $921(15.6)$ & 5.4 \\
Bronchitis & $398(6.7)$ & 2.3 \\
Sinusitis & $369(6.3)$ & 2.2 \\
Urinary tract infection & $333(5.6)$ & 2.0 \\
Influenza & $307(5.2)$ & 1.8 \\
Pharyngitis & $278(4.7)$ & 1.6 \\
Gastroenteritis & $237(4.0)$ & 1.4 \\
Patients with $\geq 1$ serious infection/ & $223(3.8)$ & 1.3 \\
infestation & & \\
Cellulitis & $40(0.7)$ & 0.2 \\
Pneumonia & $25(0.4)$ & 0.1 \\
Appendicitis & $11(0.2)$ & 0.1 \\
Erysipelas & $9(0.2)$ & 0.1 \\
\hline
\end{tabular}

$I R$ incidence rate, $N$ total number of patients, $n$ number of patients in category

${ }^{a}$ Incidence rates are per 100 patient-years

( $n=25$; IR $0.1 / 100$ p-y); appendicitis $(n=11$; IR $0.1 / 100$ p-y) and erysipelas $(n=9$; IR $0.1 /$ 100 p-y).

Latent tuberculosis was reported for 42 patients (IR 0.2/100 p-y), the mycobacterium complex test was positive for 43 patients (IR $0.2 / 100 \mathrm{p}-\mathrm{y}$ ) and the tuberculin test was positive for 17 patients (IR 0.1/100 p-y); pulmonary tuberculosis or tuberculosis was determined for one patient (IR $<0.05 / 100$ p-y) each. These findings were criteria for discontinuation for some of the studies and led to discontinuation in $20,31,13,1$ and 1 patients, respectively. There were no confirmed cases of tuberculosis reactivation; one de novo case of tuberculosis was reported in a country with a high tuberculosis burden. 


\section{Malignancies}

The most common malignancies were NMSCs (keratinocyte cancers)—specifically basal cell carcinoma ( $n=42$; IR $0.2 / 100 \mathrm{p}$-y) and squamous cell carcinomas $(n=12$; IR $0.1 / 100$ p-y) (Table 5). The total number of other malignancies was 86 (IR $0.5 / 100 \mathrm{p}$-y), with prostate cancer being the most common $(n=12$, IR in men only $0.1 / 100 \mathrm{p}-\mathrm{y})$, followed by squamous cell carcinoma ( $n=6$; IR $<0.05 / 100$ p-y for all $n \leq$ $6)$, invasive ductal breast carcinoma $(n=5)$, colon cancer $(n=4)$ and metastatic lung cancer $(n=3)$; no other specific malignancies were seen in more than two patients.

\section{Candidiasis}

Candidiasis overall was reported by 327 patients (IR 1.9/100 p-y), with oral candidiasis reported

Table 5 Malignancies

\begin{tabular}{|c|c|c|}
\hline Category & $\begin{array}{l}\text { Combined } \\
\text { ixekizumab } \\
(N=5898)\end{array}$ & $\mathbf{I R}^{\mathbf{a}}$ \\
\hline $\begin{array}{l}\text { Non-melanoma skin } \\
\text { cancer, } n(\%)\end{array}$ & $51(0.9)$ & 0.3 \\
\hline $\begin{array}{l}\text { Basal cell carcinoma, } \\
n(\%)\end{array}$ & $42(0.7)$ & 0.2 \\
\hline $\begin{array}{l}\text { Squamous cell } \\
\text { carcinoma, } n(\%)\end{array}$ & $12(0.2)$ & 0.1 \\
\hline $\begin{array}{l}\text { Malignancies excluding } \\
\text { NMSC, } n(\%)\end{array}$ & $86(1.5)$ & 0.5 \\
\hline Prostate cancer, ${ }^{\mathrm{b}} n(\%)$ & $12(0.3)$ & 0.1 \\
\hline $\begin{array}{l}\text { Squamous cell } \\
\text { carcinoma, } n(\%)\end{array}$ & $6(0.1)$ & $<0.05$ \\
\hline $\begin{array}{l}\text { Invasive ductal breast } \\
\text { carcinoma, } n(\%)\end{array}$ & $5(0.1)$ & $<0.05$ \\
\hline Colon cancer, $n(\%)$ & $4(0.1)$ & $<0.05$ \\
\hline $\begin{array}{l}\text { Lung cancer metastatic, } \\
n(\%)\end{array}$ & $3(0.1)$ & $<0.05$ \\
\hline
\end{tabular}

$I R$ incidence rate, $N$ total number of patients, $n$ number of patients in category, NMSC non-melanoma skin cancer

${ }^{a}$ Incidence rates are per 100 patient-years

b Calculated in men only; $N=4000$ men with $11,714.2$ patient-years of exposure by 140 patients (IR 0.8/100 p-y) (Table 3); one case of esophageal candidiasis led to study discontinuation; there were no reports of deep organ or bloodstream Candida infection.

\section{Inflammatory Bowel Disease}

Overall, TEAEs of IBD (narrow terms) were reported by a total of 26 patients (IR $0.2 / 100$ p-y), largely as ulcerative colitis $(n=18$; IR $0.1 /$ 100 p-y) and Crohn's disease $(n=7$, IR $<0.05 /$ 100 p-y; Table 3). Of the eight reports of Crohn's disease from seven patients, four events occurred in the first year and two each were reported in the second and fifth years of treatment. As awareness of the role of IL-17 inhibition in IBD evolved after initiation of the psoriasis clinical trial program, a protocol amendment was instituted that allowed for post hoc adjudication of IBD in a retrospective manner. Per adjudication, prespecified specific and nonspecific terms for IBD were identified and evaluated as follows: 24 patients had reported IBD confirmed as ulcerative colitis $(n=16$; IR $0.1 / 100 \mathrm{p}-\mathrm{y})$ and Crohn's disease $(n=8$; IR $<0.05 / 100 \mathrm{p}-\mathrm{y})$. As shown for unadjudicated cases (specific terms) in Fig. 3, the IR for adjudicated cases remained relatively constant over time (year $1, n=14$, IR $0.3 / 100$ p-y; year $2, n=6$, IR $0.2 / 100$ p-y; years 3 and $4, n=1$ each [each IR $<0.05 / 100 \mathrm{p}$-y]; year $5, n=4$, IR 0.2/100 p-y).

\section{Major Adverse Cardiovascular Events}

Major adverse cardiovascular events occurred in 84/5697 patients (IR 0.5/100 p-y) in studies with adjudication (total p-y 16,455.6) (Table 3). The most common category of events was nonfatal myocardial infarction $(n=45$; IR 0.3 / $100 \mathrm{p}-\mathrm{y})$, followed by vascular death $(n=20$; IR $0.1 / 100 \mathrm{p}-\mathrm{y})$ and nonfatal stroke $(n=20$; IR $0.1 / 100$ p-y).

\section{DISCUSSION}

Many factors must be considered when selecting the optimal therapy for psoriasis; important among these are the association of therapies with AEs, such as infection or malignancy, and the impact of therapy on comorbidities [23, 24]. 
We assessed safety events up to 5 years of therapy with ixekizumab in 5898 patients, for $>17,000$ total p-y of exposure. IRs of TEAEs generally decreased or remained stable over time, and the overall rate of TEAEs was lower with longer duration of therapy compared to the first 12-week placebo-controlled period. Most AEs were not serious, and the rate of discontinuation due to AEs was low, with a decreasing trend over time. The overall rate of SAEs was stable across the study period, with no trend toward increasing rates of AEs with longer duration of exposure. This was also true for rates of malignancies, MACE and serious infections, which remained comparable to those for placebo or ixekizumab during the 12-week placebo-controlled induction period. These results support and confirm previous reports describing a favorable safety profile following shorter durations of ixekizumab exposure, and suggest that increased duration and total exposure to ixekizumab were not associated with additional or unexpected safety concerns $[15,17,18]$.

Previous reports have noted infections as the most frequent $\mathrm{AE}$ associated with ixekizumab therapy. In the present report, infections were found to be generally mild to moderate in severity and seldom led to study discontinuation. The IR of severe infections (1.4/100 p-y) did not increase over time and was comparable to that reported in pooled safety data for up to 5 years of treatment with the anti-IL-12 and anti-IL-23 agent ustekinumab (1.1/100 p-y) [25], in pooled safety data primarily for 3 years for the tumor necrosis factor (TNF) inhibitor adalimumab (1.8/100 p-y) [26] and in data for up to 66 months in a single study of the Janus kinase inhibitor tofacitinib (1.2/100 p-y) [27]. There were no reports of Grade $4\left(<0.5 \times 10^{9} / \mathrm{L}\right)$ neutropenia associated with infections; an infection temporally associated with Grade 3 $\left(<1.0-0.5 \times 10^{9} / \mathrm{L}\right)$ neutropenia was reported for three patients $(0.1 \%$; influenza $[n=1]$, otitis externa $[n=1]$ and nasopharyngitis $[n=1])$ and infections associated with Grade 2 neutropenia $\left(<1.5-1.0 \times 10^{9} / \mathrm{L}\right)$ were reported for $27(0.5 \%)$ patients. Consistent with the role of IL-17A in the suppression of mucocutaneous candidiasis, oral candidiasis was the most frequently reported opportunistic infection. Positive tuberculin tests led to discontinuation (which was protocol specified for a portion of the studies) for 66 patients. However, no cases of tuberculosis reactivation have been observed in the ixekizumab clinical development program, including in patients with latent or previously treated Mycobacterium tuberculosis infection. One case of de novo tuberculosis was reported in a country with a high tuberculosis burden. ISRs were also one of the most commonly reported AEs, and their IRs declined over time, as noted in a previous analysis that used most of the current dataset [28]. Allergic reactions/hypersensitivities were more frequently reported during the first year, then stabilized or decreased moderately in subsequent years. The occurrence of potential paradoxical reactions, such as pustular psoriasis, were rare. SAEs classified as allergic reactions/hypersensitivity events and discontinuation of ixekizumab due to allergic reactions/hypersensitivities were uncommon, with $27(0.5 \%)$ and $28(0.5 \%)$ patients reporting such events, respectively. Overall, there was no indication of an increased risk for allergic reactions/hypersensitivity events with increasing durations of exposure to ixekizumab.

Findings regarding IBD in the present analysis were consistent with those of an earlier report on combined ixekizumab safety data collected over 3 years, indicating that Crohn's disease and ulcerative colitis were uncommon [18]. Annual IRs of patients with TEAEs (specific and broad terms) adjudicated (retrospective and prospective) per EPIMAD criteria as probable or definite Crohn's disease and ulcerative colitis did not increase and remained stable for up to 5 years of therapy. As noted in a previous report on IBD in patients receiving ixekizumab, which assessed approximately two-thirds of the patients included herein over shorter periods of exposure, such rates are comparable to those reported in psoriasis cohort studies, but are difficult to compare directly to rates reported in studies of other biologics due to differences in criteria for reporting events [22].

Patients with psoriasis are at an increased risk of cardiovascular AEs, including a 10-year risk of MACE [29-33]. While a reduction in cardiovascular risk has been suggested for methotrexate or biologics in the treatment of rheumatoid 
arthritis [34-36], reports on cardiovascular risk reduction with psoriasis treatment have been contradictory $[37,38]$. Low serum levels of IL-17 have been associated with a risk of repeat myocardial infarction; however, the role of IL17 in atherosclerosis is complex, with conflicting results reported [14]. In the present study, the overall incidence of MACE of 0.5/100 p-y was comparable to long-term results reported for patients receiving ustekinumab $(0.44 / 100$ p-y) [25] and adalimumab (0.36/100 p-y) [39], with no apparent increase in incidence with longer ixekizumab exposure. Determining whether biologics, including specific immunomodulators, are associated with increased, decreased or comparable rates of cardiovascular disease relative to rates in untreated patients with psoriasis or in patients receiving other psoriasis treatments will require further studies, such as observational studies or studies using claims database cohorts, and meta-analyses with large numbers of patients receiving various comparator treatments.

Patients with psoriasis may be at increased risk for some lymphoproliferative [40] and NMSC malignancies [41, 42], and there are concerns about the impact of long-term systemic treatment with anti-TNF therapies [43]. The IR of malignancies other than NMSC $(0.5 /$ $100 \mathrm{p}-\mathrm{y})$ for up to 5 years of therapy with ixekizumab in this study was comparable to that for long-term ustekinumab (0.6/100 p-y) [25] and the anti-TNF therapies adalimumab $(0.8 / 100$ p-y) [26] and etanercept (estimated 0.55/100 p-y) [44]. The IR of NMSC seen with ixekizumab of $0.3 / 100$ p-y in this study was somewhat lower than that reported based on long-term safety data for ustekinumab (0.52/100 p-y) [25] or with adalimumab (0.6/100 p-y) [26] or etanercept (0.9 per $100 \mathrm{p}$-y) [44] in psoriasis. The ratio of basal cell carcinoma to squamous cell carcinoma expected in immunocompetent patients in the general population is $4: 1$, and is reversed in severely immunocompromised patients, such as transplant recipients [45]; thus, the ratio of 3.5:1 during long-term ixekizumab dosing was consistent with the expectation for immunocompetent patients. There were 34 total deaths reported over the $17,003.4 \mathrm{p}$-y of exposure to ixekizumab; the IR of $0.2 / 100$ p-y is consistent with that reported for ustekinumab up to 5 years $(0.22 / 100$ p-y) [25]. Most deaths in this study were secondary to cardiovascular disorders in patients with background risk factors.

The limitations of the present study include the following. First, although overall IRs of AEs decreased after the 12-week induction period, some of the decreases in AEs may be due to reporting fatigue and differences in recall due to increased time between visits at later time points. Secondly, the lack of a randomized placebo control group after the induction period limited our ability to directly compare IRs at later time points with a control population. Thirdly, the length of follow-up varied between studies, and the three largest studies, UNCOVER-1, -2 and -3 , are not all completed; thus, it will be important to revisit these findings once all of the UNCOVER studies have been completed. Fourthly, certain adverse effects, such as MACE and malignancies, require longer observation periods and larger patient exposures to ascertain risk. Long-term safety studies, including post marketing studies, are ongoing to continue to evaluate the safety of ixekizumab; however, preliminary data up to 27 months from the Corrona observational database are consistent with the present results [46].

\section{CONCLUSION}

In conclusion, no new safety signals were identified with longer-term follow-up with ixekizumab, nor was any trend observed for an increase in IRs for any $\mathrm{AE}$ of special interest based on increased duration of therapy through 1-5 years. Thus, the long-term safety profile with ixekizumab up to 5 years was consistent with the favorable safety profile observed previously following shorter durations of ixekizumab exposure.

\section{ACKNOWLEDGEMENTS}

Funding. The studies described herein and the Rapid Service Fee were funded by Eli Lilly and Company. 
Medical Writing Assistance. Thomas Melby (Syneos Health) assisted as a medical writer in the preparation of this manuscript, funded by Eli Lilly and Company.

Authorship. All named authors meet the International Committee of Medical Journal Editors (ICMJE) criteria for authorship for this article, take responsibility for the integrity of the work as a whole, and have given their approval for this version to be published.

Disclosures. April Armstrong has served as a research investigator and/or consultant to AbbVie, Janssen, Lilly, Leo, Novartis, UCB, Ortho Dermatologics, Dermira, Sanofi, Regeneron, BMS, Dermavant, and Modernizing Medicine. Carle Paul has served as consultant and/or investigator for AbbVie, Amgen, Boehringer, Celgene, Eli Lilly and Company, Janssen, Leo, Novartis, and Pfizer. Luis Puig has received: grants or research support or participated in clinical trials (paid to institution) from AbbVie, Almirall, Amgen, Boehringer Ingelheim, Janssen, Leo-Pharma, Eli Lilly and Company, Novartis, Pfizer, Regeneron, Roche, Sanofi, and UCB; honoraria or consultation fees (paid to self) from AbbVie, Almirall, Amgen, Baxalta, Biogen, Boehringer Ingelheim, Celgene, Gebro, Janssen, Leo-Pharma, Eli Lilly and Company, Merck-Serono, MSD, Mylan, Novartis, Pfizer, Regeneron, Roche, Sandoz, Samsung-Bioepis, Sanofi, and UCB; and has been a speaker for Celgene, Janssen, Eli Lilly and Company, MSD, Novartis, and Pfizer. Luis Puig is also a member of the journal's Editorial Board. Wolf-Henning Boehncke has received honoraria as an advisor or speaker from the following companies: AbbVie, Almirall, Celgene, Janssen, Leo, Eli Lilly and Company, Novartis, Pfizer, and UCB. Michael Freeman has been a scientific adviser and/or investigator and/or speaker for Amgen, AbbVie, Allergan, Celgene, Dermira, Eli Lilly and Company, Galderma, Janssen, Leo Pharma, Novartis, Pfizer, Regeneron, Roche, and Sanofi/ Genzyme. Hideshi Torii has received consulting fees or honoraria from the following companies: AbbVie, Eli Lilly and Company, Celgene, Janssen, Novartis, Kyowa Hakko Kirin, and Mitsubishi Tanabe Pharma. Kim Papp has been a consultant and/or scientific adviser and/or investigator and/or scientific officer and/or speaker for Amgen, Anacor, AbbVie, Akros, Allergan, Astellas, AstraZeneca, Baxalta, Baxter, BMS, Boehringer Ingelheim, Can-Fite, Celgene, Coherus, Dermira, Dow Pharma, Eli Lilly and Company, Forward Pharma, Galderma, Genentech, GSK, Janssen, Kyowa Hakko Kirin, Leo Pharma, Medimmune, Meiji Seika Pharma, Merck (MSD), Merck-Serono, Mitsubishi Pharma, Novartis, Pfizer, Regeneron, Roche, Sanofi/Genzyme, Takeda, UCB, and Valeant. Christopher E.M. Griffiths has received honoraria and/or research grant support (University of Manchester) from AbbVie, Almirall, Bristol Meyers Squibb, Celgene, Eli Lilly and Company, GSK, Janssen, LEO Foundation, Novartis, Pfizer, Sandoz, Sun Pharma, and UCB Pharma. Andrew Blauvelt has served as a scientific adviser and/or clinical study investigator for AbbVie, Aclaris, Akros, Allergan, Almirall, Amgen, Arena, Athenex, Boehringer Ingelheim, Bristol-Myers Squibb, Celgene, Dermavant, Dermira Eli Lilly and Company, FLX Bio, Galderma, Genentech/ Roche, GlaxoSmithKline, Janssen, Leo, Meiji, Merck Sharp \& Dohme, Novartis, Pfizer, Purdue Pharma, Regeneron, Revance, Sandoz, Sanofi Genzyme, Sienna Pharmaceuticals, Sun Pharma, UCB Pharma, Valeant, and Vidac, and as a paid speaker for AbbVie, Regeneron, and Sanofi Genzyme. Kristian Reich has served as an advisor and/or paid speaker for and/or participated in clinical trials sponsored by AbbVie, Affibody, Amgen, Biogen, Boehringer Ingelheim Celgene, Centocor, Covagen, Forward Pharma, GlaxoSmithKline, Janssen-Cilag, Kyowa Kirin, Leo, Eli Lilly and Company, Medac, Merck Sharp \& Dohme, Novartis, Ocean Pharma, Pfizer, Regeneron, Sanofi, Takeda, UCB Pharma, and Xenoport. Melinda Gooderham has been an investigator, speaker, advisory board member or consultant for AbbVie, Amgen, Akros, Arcutis, Boehringer Ingelheim, Bristol-Myers Squibb, Celgene, Dermira, Dermavant, Eli Lilly and Company, Galderma, GSK, Janssen, Kyowa Kirin, LEO Pharma, Medimmune, Novartis, Pfizer, Regeneron, Roche, Sun Pharmaceuticals, UCB, and Valeant. Tadashi Terui has received research funds from Maruho Co. Ltd. and honoraria for speaker, consultancy and advisory 
board member from AbbVie, Boehringer Ingelheim, Celgene, Janssen, Kyowa Hakko Kirin Co., Ltd, Leo Pharma, Eli Lilly and Company, Mitsubishi Tanabe Pharma Corporation, Novartis, TAIHO Phamaceutical Co, and Sanofi. Mark G. Lebwohl is an employee of Mount Sinai Hospital, for which he receives research funds from: AbbVie, Amgen, AstraZeneca, BoehringerIngelheim, Celgene, Eli Lilly and Company, Incyte, Janssen/Johnson \& Johnson, Kadmon, Leo Pharmaceuticals, Medimmune, Novartis, Pfizer, Sciderm, UCB, Ortho-dermatologics, and ViDac. Mark G. Lebwohl is also a consultant for Allergan, Almirall, Arcutis, Avotres, Birch biomed, Boehringer-Ingelheim, Bristol Myers Squibb, Cara, Castle Biosciences, Dermavant, Encore, Inozyme, LEO Pharma, Meiji, Menlo, Mitsubishi Pharma, Neuroderm LTD, Pfizer, Promius/Dr. Reddy, Theravance Biopharma, and Verrica. Mark G. Lebwohl is also a member of the journal's Editorial Board. Lisa Renda is an employee and minor shareholder of Eli Lilly and Company. Noah Agada is an employee and minor shareholder of Eli Lilly and Company. Wen $\mathrm{Xu}$ is an employee and minor shareholder of Eli Lilly and Company. Gaia Gallo is an employee and minor shareholder of Eli Lilly and Company. Gaia Gallo is also a National Institute for Health Research (NIHR) Emeritus Senior Investigator and is funded in part by the NIHR Manchester Biomedical Research Centre.

Compliance with Ethics Guidelines. The protocols for all studies included in this analysis were approved by the Institutional Review Board or Ethics Committee at each participating site. All studies included in this analysis were conducted in accordance with the ethical principles of the Declaration of Helsinki. All eligible patients provided written informed consent before undergoing study-related procedures.

Data Availability. Eli Lilly and Company provides access to all individual participant data collected during the trial, after anonymization, with the exception of pharmacokinetic or genetic data. Data are available on request 6 months after the indication studied has been approved in the United States and European Union and after primary publication acceptance, whichever is later. No expiration date of data requests is currently set once data are made available. Access is provided after a proposal has been approved by an independent review committee identified for this purpose and after receipt of a signed data sharing agreement. Data and documents, including the study protocol, statistical analysis plan, clinical study report and blank or annotated case report forms, will be provided in a secure data sharing environment. For details on submitting a request, see the instructions provided at www. vivli.org.

Open Access. This article is distributed under the terms of the Creative Commons Attribution-NonCommercial 4.0 International License (http://creativecommons.org/licenses/ by-nc/4.0/), which permits any noncommercial use, distribution, and reproduction in any medium, provided you give appropriate credit to the original author(s) and the source, provide a link to the Creative Commons license, and indicate if changes were made.

\section{REFERENCES}

1. Boehncke WH, Schon MP. Psoriasis. Lancet. 2015;386(9997):983-94.

2. Rachakonda TD, Schupp CW, Armstrong AW. Psoriasis prevalence among adults in the United States. J Am Acad Dermatol. 2014;70(3):512-6.

3. Liu L, Lu J, Allan BW, et al. Generation and characterization of ixekizumab, a humanized monoclonal antibody that neutralizes interleukin-17A. J Inflamm Res. 2016;9:39-50.

4. Cypowyj S, Picard C, Marodi L, Casanova JL, Puel A. Immunity to infection in IL-17-deficient mice and humans. Eur J Immunol. 2012;42(9):2246-54.

5. Gaffen SL, Hernandez-Santos N, Peterson AC. IL-17 signaling in host defense against Candida albicans. Immunol Res. 2011;50(2-3):181-7.

6. Peck A, Mellins ED. Precarious balance: Th17 cells in host defense. Infect Immun. 2010;78(1):32-8.

7. Puel A, Cypowyj S, Bustamante J, et al. Chronic mucocutaneous candidiasis in humans with inborn 
errors of interleukin-17 immunity. Science. 2011;332(6025):65-8.

8. Fujino $\mathrm{S}$, Andoh $\mathrm{A}$, Bamba $\mathrm{S}$, et al. Increased expression of interleukin 17 in inflammatory bowel disease. Gut. 2003;52(1):65-70.

9. Hueber W, Sands BE, Lewitzky S, et al. Secukinumab, a human anti-IL-17A monoclonal antibody, for moderate to severe Crohn's disease: unexpected results of a randomised, double-blind placebo-controlled trial. Gut. 2012;61(12): 1693-700.

10. O'Connor W Jr, Kamanaka M, Booth CJ, et al. A protective function for interleukin $17 \mathrm{~A}$ in $\mathrm{T}$ cellmediated intestinal inflammation. Nat Immunol. 2009;10(6):603-9.

11. Strober W, Fuss IJ. Proinflammatory cytokines in the pathogenesis of inflammatory bowel diseases. Gastroenterology. 2011;140(6):1756-67.

12. Targan SR, Feagan B, Vermeire $S$, et al. A randomized, double-blind, placebo-controlled phase 2 study of brodalumab in patients with moderate-tosevere Crohn's disease. Am J Gastroenterol. 2016;111(11):1599-607.

13. Tang C, Kakuta S, Shimizu K, et al. Suppression of IL-17F, but not of IL-17A, provides protection against colitis by inducing Treg cells through modification of the intestinal microbiota. Nat Immunol. 2018;19(7):755-65.

14. Taleb S, Tedgui A, Mallat Z. IL-17 and Th17 cells in atherosclerosis: subtle and contextual roles. Arterioscler Thromb Vasc Biol. 2015;35(2):258-64.

15. Griffiths CE, Reich K, Lebwohl M, et al. Comparison of ixekizumab with etanercept or placebo in moderate-to-severe psoriasis (UNCOVER-2 and UNCOVER-3): results from two phase 3 randomised trials. Lancet. 2015;386(9993):541-51.

16. Reich K, Pinter A, Lacour JP, et al. Comparison of ixekizumab with ustekinumab in moderate-to-severe psoriasis: 24-week results from IXORA-S, a phase III study. Br J Dermatol. 2017;177(4):1014-23.

17. Strober B, Leonardi C, Papp KA, et al. Short- and long-term safety outcomes with ixekizumab from 7 clinical trials in psoriasis: etanercept comparisons and integrated data. J Am Acad Dermatol. 2017;76(3):432-40.

18. Langley RG, Kimball AB, Nak $\mathrm{H}$, et al. Long-term safety profile of ixekizumab in patients with moderate-to-severe plaque psoriasis: an integrated analysis from 11 clinical trials. J Eur Acad Dermatol Venereol. 2019;33(2):333-9.
19. Gordon KB, Blauvelt A, Papp KA, et al. Phase 3 trials of ixekizumab in moderate-to-severe plaque psoriasis. N Engl J Med. 2016;375(4):345-56.

20. Ryan C, Menter A, Guenther L, et al. Efficacy and safety of ixekizumab in a randomized, doubleblinded, placebo-controlled phase IIIb study of patients with moderate-to-severe genital psoriasis. Br J Dermatol. 2018;179(4):844-52.

21. Gower-Rousseau C, Salomez JL, Dupas JL, et al. Incidence of inflammatory bowel disease in northern France (1988-1990). Gut. 1994;35(10):1433-8.

22. Reich K, Leonardi C, Langley RG, et al. Inflammatory bowel disease among patients with psoriasis treated with ixekizumab: a presentation of adjudicated data from an integrated database of 7 randomized controlled and uncontrolled trials. J Am Acad Dermatol. 2017;76(3):441-8.

23. Kaushik SB, Lebwohl MG. Psoriasis: which therapy for which patient: focus on special populations and chronic infections. J Am Acad Dermatol. 2019;80(1):43-53.

24. Kaushik SB, Lebwohl MG. Psoriasis: which therapy for which patient: psoriasis comorbidities and preferred systemic agents. J Am Acad Dermatol. 2019;80(1):27-40.

25. Papp KA, Griffiths CE, Gordon K, et al. Long-term safety of ustekinumab in patients with moderate-tosevere psoriasis: final results from 5 years of followup. Br J Dermatol. 2013;168(4):844-54.

26. Leonardi C, Papp K, Strober B, et al. Comprehensive long-term safety of adalimumab from 18 clinical trials in adult patients with moderate-to-severe plaque psoriasis. Br J Dermatol. 2019;180(1):76-85.

27. Valenzuela F, Korman NJ, Bissonnette R, et al. Tofacitinib in patients with moderate-to-severe chronic plaque psoriasis: long-term safety and efficacy in an open-label extension study. Br J Dermatol. $2018 ; 179(4): 853-62$.

28. Shear NH, Paul C, Blauvelt A, et al. Safety and tolerability of ixekizumab: integrated analysis of injection-site reactions from 11 clinical trials. J Drugs Dermatol. 2018;17(2):200-6.

29. Gelfand JM, Neimann AL, Shin DB, et al. Risk of myocardial infarction in patients with psoriasis. JAMA. 2006;296(14):1735-41.

30. Kaye JA, Li L, Jick SS. Incidence of risk factors for myocardial infarction and other vascular diseases in patients with psoriasis. Br J Dermatol. 2008;159(4): 895-902. 
31. Mehta NN, Azfar RS, Shin DB, et al. Patients with severe psoriasis are at increased risk of cardiovascular mortality: cohort study using the General Practice Research database. Eur Heart J. 2010;31(8): 1000-6.

32. Mehta NN, Yu Y, Pinnelas R, et al. Attributable risk estimate of severe psoriasis on major cardiovascular events. Am J Med. 2011;124(8):775-6.

33. Abuabara K, Azfar RS, Shin DB, et al. Cause-specific mortality in patients with severe psoriasis: a population-based cohort study in the UK. Br J Dermatol. 2010;163(3):586-92.

34. Micha R, Imamura F, von Wyler BM, et al. Systematic review and meta-analysis of methotrexate use and risk of cardiovascular disease. Am J Cardiol. 2011;108(9):1362-70.

35. Westlake SL, Colebatch AN, Baird J, et al. Tumour necrosis factor antagonists and the risk of cardiovascular disease in patients with rheumatoid arthritis: a systematic literature review. Rheumatology (Oxford). 2011;50(3):518-31.

36. Westlake SL, Colebatch AN, Baird J, et al. The effect of methotrexate on cardiovascular disease in patients with rheumatoid arthritis: a systematic literature review. Rheumatology (Oxford). 2010;49(2):295-307.

37. Wu JJ, Joshi AA, Reddy SP, et al. Anti-inflammatory therapy with tumour necrosis factor inhibitors is associated with reduced risk of major adverse cardiovascular events in psoriasis. J Eur Acad Dermatol Venereol. 2018;32(8):1320-6.

38. Abuabara K, Lee H, Kimball AB. The effect of systemic psoriasis therapies on the incidence of myocardial infarction: a cohort study. Br J Dermatol. 2011;165(5):1066-73.
39. Leonardi C, Papp K, Strober B, et al. The long-term safety of adalimumab treatment in moderate to severe psoriasis: a comprehensive analysis of all adalimumab exposure in all clinical trials. Am J Clin Dermatol. 2011;12(5):321-37.

40. Brauchli YB, Jick SS, Miret M, Meier CR. Psoriasis and risk of incident cancer: an inception cohort study with a nested case-control analysis. J Invest Dermatol. 2009;129(11):2604-12.

41. Krathen MS, Gottlieb AB, Mease PJ. Pharmacologic immunomodulation and cutaneous malignancy in rheumatoid arthritis, psoriasis, and psoriatic arthritis. J Rheumatol. 2010;37(11):2205-15.

42. Frentz G, Olsen JH. Malignant tumours and psoriasis: a follow-up study. Br J Dermatol. 1999;140(2): 237-42.

43. Patel RV, Clark LN, Lebwohl M, Weinberg JM. Treatments for psoriasis and the risk of malignancy. J Am Acad Dermatol. 2009;60(6):1001-17.

44. Papp KA, Poulin Y, Bissonnette R, et al. Assessment of the long-term safety and effectiveness of etanercept for the treatment of psoriasis in an adult population. J Am Acad Dermatol. 2012;66(2): e33-45.

45. Rubin AI, Chen EH, Ratner D. Basal-cell carcinoma. N Engl J Med. 2005;353(21):2262-9.

46. Grace E, Zhu B, Malley W, et al. Safety events occurring among patients exposed to ixekizumab in the Corrona Psoriasis Registry. Poster presented at: 6th Congress of the Skin Inflammation and Psoriasis International Network; 25-27 April 2019; Paris, France. J Eur Acad Dermatol Venereol 33[S3]:P001. https://doi.org/10.1111/jdv.15512. 